Indexaciones: Repositorio de Revistas UCR, DIALNET, Latindex, REDALYC Directorio y recolector de recursos digitales del Ministerio de Cultura de España, Directory of Open Access Journals. Diálogos Revista Electrónica de Historia ISSN 1409-469X. Número especial 2008. Dirección web: http://historia.fcs.ucr.ac.cr/dialogos.htm

\title{
Nicaragua 13 de diciembre de 1995: \\ Por la Defensa del 6\% y la Autonomía Universitaria.
}

\author{
Edgard Palazio Galo
}

Managua, Nicaragua. Villa Don Bosco, Casa D-49. Teléfono 8285436.

Email: Edgardpalazio@yahoo.com Universidad Nacional Autónoma de Nicaragua

UNAN-Managua 


\section{Contexto de la Lucha Universitaria en 1995. Ley de Reformas a la Ley de Régimen Presupuestario.}

En 1995 el Gobierno de la presidenta Violeta Barrios de Chamorro y la Asamblea Nacional (A.N.) se vieron envueltos en un agitado duelo político, siendo uno de los motivos el proceso de reformas a la Constitución Política propiciado por la A. N. Este conflicto entre ambos poderes del Estado, finalmente fue resuelto el 14 de junio, mediante un acuerdo político sellado con la aprobación de la Ley No. 199, Ley Marco de Implementación de las Reformas Constitucionales. ${ }^{1}$ Reformas que fueron incluidas en la Ley No. 192 de Reforma Parcial de la Constitución Política. ${ }^{2}$

De diferentes formas las leyes número 192 y 199 fueron incidentes para las Universidades y Centros de Educación Técnica Superior aglutinados en el Consejo Nacional de Universidades (C.N.U.). En primer lugar, la Ley No. 192 de Reforma Parcial de la Constitucional Política fue favorable pues permitió elevar al rango constitucional el 6\%, en su efecto, la Ley No. 199, Ley Marco de Implementación de las Reformas Constitucionales por su medio fue posible la

1 Para mayor detalle ver texto de la Ley No. 199, Ley Marco de Implementación de las Reformas Constitucionales. La Gaceta No. 125. Managua, 5 de julio de 1995. La Ley Marco tuvo vigencia desde julio de 1995 al 1 de enero de 1997. Si bien la Ley Marco de Implementación de las Reformas Constitucionales fue un acuerdo político que permitió superar la crisis institucional del momento, también fue considerada como una aberración jurídica y un atentado contra la propia constitucionalidad del país. Pues no se entendía cómo la virtualidad jurídica de la Constitución Política dependiera de lo dispuesto por una norma de rango inferior. Ver: Álvarez Argüello, Gabriel y Vintro Castells, Joan. Reformas constitucionales y evolución política en Nicaragua 1995-2003. s/d 2 Aprobada el 25 de noviembre de 1994 en primera legislatura y el primero de febrero de 1995 en segunda y definitiva legislatura. El texto de la Ley No. 192 fue remitido a la Presidenta de la República para su promulgación y publicación, una vez transcurrido el plazo establecido por la Ley y sin haber procedido a ello, la A. N. mandó a publicar la Ley el 24 de febrero de 1995. 
reforma a la Ley No. 51, Ley del Régimen Presupuestario originando el ardid esgrimido por el Gobierno de Violeta Barrios de Chamorro para cambiar el método de cálculo del $6 \%$ del Presupuesto General de la República correspondiente al año 1996.

\begin{tabular}{|c|l|}
\hline $\begin{array}{c}\text { Antes de la reforma a la } \\
\text { Ley de Régimen Presupuestario }\end{array}$ & $\begin{array}{l}\text { Después de las reformas a la } \\
\text { Ley de Régimen Presupuestario }\end{array}$ \\
\hline Ingresos Ordinarios & Ingresos \\
no tributarios & Ingreso corrientes Ordinarios \\
Ingresos de Capital & Ingresos de capital (extraordinarios) \\
\hline $\begin{array}{c}\text { Ingresos extraordinarios } \\
\text { Donaciones }\end{array}$ & $\begin{array}{c}\text { Financiamiento del déficit } \\
\text { Financiamiento del déficit }\end{array}$ \\
\hline
\end{tabular}

Fuente: Patrick Dumazert. La batalla del $6 \%$ reflejo de una crisis de la sociedad y el Estado. Nitlapán - U.C.A. 7 de febrero de 1996. Pág. 5

\section{Ley No. 231, Ley Anual de presupuesto General de la República para 1996}

Con el marco de referencia propiciado por las reformas, la Ley No. 231, Ley Anual de Presupuesto 1996 aprobada por la A.N. el 15 de diciembre de 1995, amerita señalar sus particularidades; tanto por la forma errada en que el Poder Ejecutivo calculó el 6 \%, como por las violaciones cometidas contra la Constitución Política y leyes ordinarias.

De la misma forma, aunque el Art. 112 de la Constitución Política establece que los Ingresos y Egresos del Presupuesto General de la República deben ser concordantes entre si. El Presupuesto de la República para 1996 presentó el inverosímil caso de mostrar como 
ingresos un monto de $\mathrm{C} \$ 3,304,737,306$ y en egresos un total de $C \$ 4,685,183,396$ Lejos de la concordancia entre Ingresos y Egresos señalada por el Art. 112 constitucional, aconteció el hecho de tener más egresos que los ingresos reflejados. La diferencia se produjo por las definiciones conceptuales creadas por la reforma a la Ley de Régimen Presupuestario que quitó del concepto de ingresos lo que eran donaciones y préstamos, introduciéndolos en una nueva categoría presupuestaria definida como financiamiento al déficit. Indudablemente, el cambio se concibió con el propósito de disminuir la base de cálculo del aporte estatal para las universidades.

De manera que el presupuesto de $\mathrm{C} \$ 198,300,000.00$ en concepto del $6 \%$ asignado a las instituciones del C.N.U. fue calculado exclusivamente sobre la base de los Ingresos Ordinarios, no sobre los ingresos totales del Presupuesto General de la República, violando de esa forma el Art.125 de la Constitución Política. También se violó este mismo artículo constitucional al establecer para las universidades una distribución presupuestaria dividida en Gastos Corrientes y Gastos de Capital, ya que el párrafo $1^{\circ}$ del mismo Art. 125 establece:

“Las Universidades y Centros de Educación Técnica Superior, gozan de autonomía académica, financiera, orgánica y administrativa, de acuerdo con la Ley" 3

Por tanto, en apego a su autonomía le corresponde exclusivamente a las Instituciones de Educación Superior y no al Estado establecer la forma en que van a distribuir su presupuesto. ${ }^{4}$ Ese era el

$3 \quad$ Ver Artículo 125 de la Constitución Política.

4 Recordemos que en 1992 la Comunidad Universitaria ante una situación similar introdujo un recurso de Inconstitucionalidad ante la Corte Suprema de Justicia (C.S.J.) y medi- 
contexto de irregularidades y violaciones a la Constitución Política y leyes ordinarias cometidas por el gobierno que daban fundamento y legitimidad a la lucha de las universidades en 1995.

\section{Consejo Central de U.N.E.N. sábado 7 de octubre.}

Por la mañana del sábado 7 de octubre, los miembros del Consejo Central de U.N.E.N. ${ }^{5}$ se reúnen para analizar la situación generado por las acciones del Gobierno y asumen de consenso emprender la lucha en defensa del 6 \% y la Autonomía Universitaria, preparándose una campaña de protesta en torno a Unidad de todos los sectores universitarios, Seis por ciento innegociables, Conseguir el apoyo institucional y Firmar un compromiso en que se congelaran los aranceles de matrícula.

A partir de entonces la labor primordial del Movimiento Estudiantil estuvo enfocada en alcanzar una dinámica que fortaleciera su proyección dentro de la Comunidad Universitaria, enfatizando en tareas de convocatoria y movilización a las que desde ese momento se dio inicio. No fue una tarea del todo fácil, muchas estructuras del movimiento estudiantil estaban disgregadas y con relativa legitimidad. Tres días después del Consejo Central, el martes 10 de octubre el C.N.U. se declara en sesión permanente para dar seguimiento a la discusión del proyecto de Ley de Presupuesto General de la República.

ante sentencia No. 113 del 21 de junio de 1992, la C. S. J. declaró inaplicables las normas que intervengan o determinen las formas de distribución del Presupuesto Universitario. No está de mas expresar que según el Art. 167 de la Constitución Política; "Los fallos de resoluciones de los tribunales y jueces son de ineludible cumplimiento para las autoridades del Estado, las organizaciones, las personas naturales y jurídicas afectadas".

5 El Consejo Central de U.N.E.N. está conformado por el Secretariado Nacional de U.N.E.N., los Presidentes de recinto u/o universidades, los presidentes de facultad, escuela, asociaciones y una cantidad invitada de responsables de grupos. 
Una semana mas tarde, el miércoles 18 de octubre, después de hacer esfuerzos de convocatoria y aún con relativa participación, se inicia la protesta universitaria. A las 10 am desde la U.C.A. hacia la A.N. En esa coyuntura la dirigencia de U.N.E.N. mostraba confianza en crear la motivación adecuada y lograr creciente participación de los estudiantes en la protesta. Con ese objetivo se estableció como tarea principal realizar asambleas informativas en los diferentes recintos universitarios y explicar a los estudiantes las repercusiones del problema con el 6 \%.

Es importante resaltar la disposición firme en el discurso y en las acciones, de parte de la dirigencia estudiantil, ante la amenaza del Gobierno de Violeta Barrios de Chamorro. Gobierno al que tres años atrás, durante la jornada de protesta de 1992, la Comunidad Universitaria había enfrentado durante 47 días de lucha cívica, incluyendo 11 de huelga de hambre. En esa ocasión, la Comunidad Universitaria obtuvo una victoria jurídica y moral. La Corte Suprema de Justicia (C.S.J.) mandó se respetara la Ley de Autonomía Universitaria y la A.N. aclaró, en una dramática votación, el 18 de agosto de 1992, la interpretación auténtica de dicha ley. Estableciendo que el $6 \%$ se debía calcular sobre el Presupuesto General de los Ingresos Ordinario y Extraordinarios.

La preocupación de los dirigentes de U.N.E.N. tenía como fundamento, la relación con un Gobierno que contrario a plantear un diálogo propositivo y establecer relaciones constructivas con las universidades, lamentablemente se enfrentaba a ellas. En un absurdo inverosímil, explicable desde la mentalidad reaccionaria y neoliberal en la forma de conducir la política social del Estado. Considerando la inversión en educación un gasto y no una inversión en 
capacitar el capital humano que nuestro país tanto requiere.

\section{Denuncia del C.N.U. y Marcha del 23 de noviembre}

El viernes 17 de noviembre, los rectores del C.N.U. en conferencia de prensa, denuncian ante la opinión pública nacional e internacional al gobierno de la presidenta Violeta Barrios de Chamorro por violar la Constitución Política, planeando entregar menos del 6 \%, bajo la figura del proyecto de reformas a la Ley de Régimen Presupuestario. Era una situación compleja la que enfrentaban las universidades, frente un Gobierno cuyo propósito era reducir el presupuesto estatal del $6 \%$. En esas circunstancias, el lunes 20 de noviembre el C.N.U. emite un comunicado en que demanda al gobierno fiel cumplimiento a lo preceptuado en el Art. 125 de la Constitución Política. De modo que, como lo manda la ley, las Universidades y los Centros de Educación Técnica Superior que deben ser financiados por el Estado recibieran un aporte igual al $6 \%$ del Presupuesto General de la República, respetándose la autonomía de los mismos, sin condicionar la distribución del aporte entre transferencias corrientes y de capital.

Con el proyecto de Ley de Presupuesto en la A.N., la Comunidad Universitaria incrementó las movilizaciones y acciones de denuncia, reclamando el respeto al Estado de derecho. Se dirigieron múltiples esfuerzos a buscar apoyo de los diputados para que aprobaran una ley que respetará el precepto constitucional. En esos esfuerzos el apoyo incondicional de la bancada del FSLN fue siempre un factor importante. Sin embargo, consciente de la difícil correlación de fuerzas en el seno de la AN, integrada en su mayoría por diputados de derecha adversos a las universidades, el CNU mantuvo como perspectiva, buscar una solución flexible dentro del marco del Estado de derecho. 
El panorama político en el seno de la Asamblea Nacional no lucia del todo favorable, en el sentido de lograr alcanzar consenso alrededor del presupuesto universitario. Existían voces fundamentalistas insistentes en un abierto desacato a lo establecido constitucionalmente.

\section{Formación del Comité Universitario por la Defensa de la Constitución y el 6\%}

Para maximizar las acciones de protesta era estratégico proponer una expresión de lucha que decididamente articulara a todos los sectores universitarios. A esto se le brindó un decidido trabajo, formándose el 28 de noviembre entre UNEN, FESITUN ${ }^{6}$ y FEPDES-ATD ${ }^{7}$, el Comité Universitario por la Defensa de la Constitución y el 6 \%.

Era importante alcanzar la participación amplia de los miembros de la Comunidad Universitaria en función de elevar la lucha contra el Gobierno y a su vez vincularse a la sociedad en busca de respaldo. Por eso en el documento constitutivo del Comité Universitario por la Defensa de la Constitución y el 6 \% se reconocía “debemos tener la capacidad de incorporar al resto de la sociedad a esta dinámica de lucha."”.

\section{Estado de Emergencia Universitaria}

En la tarde del jueves 30 de noviembre, estudiantes de diferentes universidades se movilizan en algunos puntos céntricos de Managua solicitando firmas de apoyo y realizan tranques

$6 \quad$ Federación Sindical de Trabajadores Universitarios

$7 \quad$ Federación de Educadores de la Educación Superior-Asociación de Trabajadores Docentes

8 Ídem. Pág. 4 
en El Dancing sobre la carretea norte, en el Kilometro 7 de la carretera sur y en los semáforos de la Colonia Centroamérica. ${ }^{9}$ Fortaleciendo las actividades impulsadas por el Movimiento Estudiantil, el miércoles 1 de diciembre el CNU declara: "Estado de Emergencia Universitaria". Haciendo saber que se mantendría en sesión permanente, "mientras no se reconozca por el Gobierno el seis por ciento del Presupuesto, que por precepto constitucional le corresponde como aporte estatal para su funcionamiento, y se respete la Autonomía Universitaria". ${ }^{10}$

El comunicado del CNU también señalaba, que el Proyecto de Ley del Presupuesto General de la República para 1996, enviado a la Asamblea Nacional por el Poder Ejecutivo, incluía un aporte para las Instituciones miembros del C.N.U., de 4.23\% del Presupuesto propuesto, a diferencia de los años de 1991, 1993, 1994 y 1995 cuando, después de reiteradas demandas y movilizaciones de la Comunidad Universitaria para lograr la rectificación de arbitrarias interpretaciones del Poder Ejecutivo, el aporte alcanzó el seis por ciento del Presupuesto aprobado por la Asamblea Nacional. ${ }^{11}$

Para el mes de diciembre de 1995, el Comité Nacional de UNEN había planificado un conjunto de actividades que incluían marchas nocturnas, visita a medios de comunicación, cabildeo con diputados, tomas de edificios públicos, asambleas universitarias, etc. Previendo realizar para el 13 o 15 de diciembre (posibles fechas de discusión del Presupuesto General de la República), 9 Como aclaración a los futuros estudiantes universitarios entonces no existía el paso a desnivel de la colonia Centroamérica.

10 Comunicado del C.N.U., declaración de Estado de Emergencia Universitario. Managua. 1 de diciembre de 1995. Ver anexo No. 2.

11 Ibídem. 
una marcha de todas las universidades hacia la A.N.

Conforme con este plan, se realizan sendas marchas de "Las Candelas de la Inteligencia".

Las noches del lunes 4 y miércoles 6 de diciembre, miles de universitarios se reconcentran en el Barrio San Judas y La Primero de Mayo respectivamente y marchan hacia la UCA. En esas frescas noches de diciembre, alumbrados con candelas recorren los barrios orientales y occidentales de Managua, agitan la noche con consignas del $6 \%$ y canciones juveniles.

\section{Huelga de hambre}

En el ínterin, e inicialmente forjada como una iniciativa estudiantil al margen de la coordinación de la UNEN, pero luego articulada al diseño general de la protesta, siete estudiantes de diferentes universidades se declaran en huelga de hambre en la tarde del martes 5 de diciembre. Luego, se integrarían nuevos compañeros y en su momento culminante la huelga de hambre llegó a estar formada por 14 compañeros que mantuvieron 16 agotadores y difíciles días de ayuno.

\section{Reunión Comité Nacional de UNEN y la Formación de Brigadas}

El 5 de diciembre en reunión del Comité Nacional de UNEN se asume como resolución subir el nivel a las acciones de protestas, orientando la formación de destacamentos estudiantiles en cada universidad, conocidos como "Las Brigadas". Las Brigadas se conformaron con estudiantes mujeres y hombres voluntarios. Dispuestos en tiempo y forma al cumplimiento tareas y acciones de protesta planificadas. Asimismo, se formó una brigada con estudiantes de la Facultad de Medicina y del Polisal, encargados de proporcionar ayuda médica en caso de 
ocurrir una situación de emergencia. Además, se constituyó dentro del Comité Nacional, una comisión integrada por tres compañeros presidentes de recintos y por el presidente nacional de UNEN, encargados de planificar las acciones de protestas que implicara mayor sincronización y discreción, presentándoselas luego al Comité Nacional para su aprobación. ${ }^{12}$

La formación de estas Brigadas tuvo como propósito que sus miembros se movilizaran a la cabeza en la protesta por el 6\%. Permitió constar con un núcleo permanente de estudiantes dispuestos a movilizarse, siendo a su vez, catalizadores de convocatoria y movilización de la Comunidad Universitaria en general. Estas compañeras y compañeros realizaron tareas de agitación y propaganda, convocaron a movilización en aquellos recintos donde el trabajo de UNEN era débil, encabezaron marchas, realizaron tomas de edificios públicos. Sobre ellos se llegó a sostener la resistencia principal de la protesta en los enfrenamientos con las fuerzas represivas de la policía.

Las Brigadas se convirtieron en el vértice del Movimiento Estudiantil, eje medular en el cumplimiento de las acciones de protesta. De estas brigadas se podría afirmar lo de Pierre Duteiul para los estudiantes de la Francia del 68: "Pocos numerosos, pero decididos, desordenados en la discusión, pero ordenados en la acción, no creen representar a los estudiantes en su conjunto, sino ser una especie de vanguardia (...)"13

12 Comisión integrada por Arístides Tablada presidente de U.N.E.N. de la U.N.A.; Edgard Palazio Galo presidente de U.N.E.N. del R.U.R.D.; Elías Velázquez presidente de U.N.E.N. de la U.C.A. y Julio Orozco Molinares presidente nacional de U.N.E.N.

13 Jean Pierre Duteuil. La revolución Estudiantil. México. De. Eva. 1969. Pág. 15. 


\section{Acciones de las Brigadas}

En la mañana del miércoles 6 de diciembre las Brigadas tuvieron sus primeras acciones. En la ciudad de León, estudiantes universitarios se toman las graderías del Estadio Héroes y Mártires durante un juego de beisbol entre los equipos Boér-León y realizan propaganda por el $6 \%$. A las 11:30 a.m. de este mismo día, en la ciudad de Managua, miembros de las Brigadas del $6 \%$ se toman por algunas horas el Ministerio de Finanzas ${ }^{14}$ y abandonan el edificio pacíficamente por medio de la intermediación de la Dra. Vilma Núñez de Escorcia, Directora del CENIDH. Estas acciones ocupaban mayor cobertura en los medios de comunicaciones, y por tanto, estimulaban en el ámbito nacional la causa del 6 \%.

La lucha por el 6 \% en 1995 tenía como límite legal para que la A.N. discutiera el proyecto de Ley de Presupuesto, el 15 de diciembre como fecha última establecida por ley. Este limitante en el tiempo hizo necesario incrementar acciones de protestas que lograran mediáticamente presionar al Gobierno y conseguir mayor atención y solidaridad ciudadana hacia el problema universitario.

Era importante, sacar el conflicto de un marco de enfrentamiento Estado-Universidad y conseguir que se viera como lo que es, un tema de índole nacional y de afectación general al país y al futuro de las nuevas generaciones. En este contexto se incrementaron las marchas a los barrios de Managua, las visitas a los mercados capitalinos, las tareas de cabildeo con diputados de diferentes bancadas y se ejecutan tomas de edificios estatales

El lunes 11 de diciembre, a las 11 a. m., las brigadas universitarias se toman el Ministerio de 14 Diario Barricada. jueves 7 de diciembre de 1995. Año 17. No. 5808. Pág. 2 
Educación y demandan que el ministro Humberto Belli se retracte de declaraciones en las que había expresado oponerse al 6 \% porque, según él, la entrega "iría a manos de la burocracia sandinista que se atrinchera en las universidades, en detrimento de la educación media". ${ }^{15}$

En ese momento, al valorar el desarrollo de la lucha, los dirigentes de UNEN estimaban que uno de los objetivos que se estaban cumpliendo era “(...) convertir el tema de la Educación en un tema nacional (...)" ${ }^{16}$ Horas después de la toma del MED, en la tarde del 11 de diciembre, se realiza la toma de las instalaciones de Telcor Villa Fontana.

A las 11 a. m. del martes 12, se produce una acción de protesta de impacto en la opinión pública. La UNEN dirige la toma durante 5 horas aproximadamente, del aeropuerto internacional Augusto Cesar Sandino. Se atrae cobertura de los medios de prensa nacional e internacionales, manteniendo en la opinión pública la problemática del presupuesto universitario.

A las 2:30 p. m. los estudiantes universitarios que marchaban desde Jinotepe llegan a Managua y de inmediato se suman a la toma de las instalaciones del aeropuerto respaldando en número a quienes allí permanecían. La toma del aeropuerto internacional generó mucha tensión, en algún momento se esperaba que la Policía intentara desalojar por la fuerza las instalaciones lo que eventualmente hubiera desencadenado un enfrentamiento con imprevisibles resultados.

No obstante, parece ser la serena posición de los miembros del Ejército de Nicaragua responsable por la seguridad del aeropuerto y la intervención del CENIDH, contribuyeron

15 Diario Barricada, martes 12 de diciembre de 1995. Año 17. No. 5812. Pág. 1 y 8. 16 La Prensa, 8 de diciembre de 1995. Edición No. Pág. 5. 
con tranquilizar la situación. La Dra. Vilma Núñez presidenta de este centro humanitario, se presentó en el lugar y por su intermediación se logra una reunión, entre los dirigentes de UNEN, el Jefe de la Policía en Managua, Pedro Aguilar; como resultado de la reunión, se acordó que la toma finalizaría a las 4: $00 \mathrm{p} \cdot \mathrm{m} \cdot{ }^{17}$

La toma del Aeropuerto Internacional dimensionó la lucha por el 6\%, sobretodo en una línea de tiempo que tenía como fecha límite de acuerdo con la ley, hasta el 15 de diciembre para que la A.N. discutiera el Presupuesto General de la República. No obstante, esta toma fue reprobada por sectores hostiles a las universidades. Según ellos, esta línea de acción no conducía a ningún lugar y, además, era cuestionable.

La atención de la prensa escrita a esta toma merece destacarse, mientras El Nuevo Diario tituló su primera plana "Toman Aeropuerto" y el diario Barricada "Espectacular acción por el 6\%, toman aeropuerto". El diario La Prensa, señaló: “Autoridad Avasallada en el Aeropuerto” y en su editorial tendenciosamente se podía leer:

“(...) si gente extraña a las aulas se infiltra para provocar peligrosos motines y avasallar a la autoridad, al extremo de ponerla en ridículo, se tiene que pensar en que esa autoridad, o es cómplice o actúa con temor a intereses poderosos escondidos"18

Del titular del diario La Prensa y del contenido de su editorial dimanaba, entre líneas, la inmanente incitación hacia la Policía a no dejarse avasallar. Viendo la forma y no el fondo que originaba el problema, el irrespeto del Gobierno a la Constitución Política, negándose calcular

17 El Nuevo Diario. Miércoles 13 de diciembre de 1995. Año XVI. No. 5509. Pág. 2.

18 La Prensa. Miércoles 13 de diciembre de 1995. Edición No. 20425. Pág. 1. 
el $6 \%$ de acuerdo con la ley. ${ }^{19}$

\section{Reunión CNU- Comisión Económica de la AN}

Por la mañana de este martes 12 de diciembre, antes de producirse la toma del aeropuerto, algunos miembros del CNU se reunieron con los miembros de la Comisión Economía de la A.N. sin obtener ninguna salida positiva a la demanda universitaria. Las razones del Gobierno son políticas y no económicas, señalaron los rectores, puntualizando "son razones políticas de confrontación con las universidades. ${ }^{’ 20}$

En aquel momento, estaba convocada para el miércoles 13 de diciembre, probable fecha de discusión del presupuesto, una marcha de todas las universidades hacia la A.N. En consecuencia, el C.N.U. mediante una carta pública se dirige a los diputados exhortándoles apoyar la causa universitaria con su voto positivo a favor del 6\% y el respeto a la Autonomía Universitaria, advirtiendo las graves consecuencias que podían generarse ante el irrespeto de un derecho fundamental para la sociedad y particularmente para la Comunidad Universitaria nicaragüenses.

19 Luego veríamos quizás algún sentido de culpa o complicidad encerrado en la línea editorial de este diario cuando después de la masacre del 13 de diciembre, en su edición del 14 de diciembre minimizó totalmente los hechos ocurridos, mientras los otros diarios de circulación nacional destacaron en primera plana la masacre perpetrada por la Policía Nacional. Para establecer esta comparación con mayor detalle recomiendo ver los titulares e información de los diarios nacionales del jueves 14 de diciembre de 1995.

20 Barricada. Miércoles 13 de diciembre de 1995. Año XVI. No. 5813. Pág. 2. 


\section{Campañas de desinformación contra las universidades}

Ante la bien estructura protesta universitaria, que a su favor se sumaba el creciente respaldo ciudadano, sin mayores argumentos que los artificios, el Gobierno de Violeta Barrios de Chamorro trató de restar legitimidad a lucha universitaria. Repitiendo lo hecho en 1992; una vil campaña de desinformación en contra de las universidades del C.N.U. ${ }^{21}$ Se dieron la tarea de publicar en los medios de prensa escrita, radial y televisiva, campos pagados, manipulando cifras y datos y contraponer el Sistema de Educación Básica ante la Educación Superior.

Como principal abanderado de tal despropósito figuró el propio Ministro de Educación Humberto Belli, ${ }^{22}$ que asumió una posición de hostilidad contra la Comunidad Universitaria, llegando a manifestar el miércoles 6 de diciembre que estaba en contra que las universidades del C.N.U. recibieran el $6 \%$, por considerar, según él, que la educación primaria y secundaria necesitaban mayores recursos. Este Ministro en su afán visceral contra las universidades del C.N.U. e irrespeto a la inteligencia y dignidad estudiantil, se dio la tarea de publicar un artículo de opinión que tituló ¿voracidad universitaria? en el cual expresaba lo siguiente:

“¿Se lograran las pretensiones de los rectores? Quizás. Refugio de la izquierda y de numerosos ortodoxos, hambrientos de mas presupuesto estatal, las universidades públicas cuentan con suficientes estudiantes manipulables, hábiles en usar las tácticas intimidatorias de siempre

21 Las campañas de desinformación contra las universidades del C.N.U. fue un vil recurso que también utilizaron los Gobiernos de Enrique Bolaños Gayer y Arnoldo Alemán.

22 Véase campos pagados por el Gobierno y el Ministerio de Educación: "La Nación es testigo, aclaraciones sobre 6\% de las universidades". En Barricada, martes 12 y miércoles 13 de diciembre de 1995 y El Nuevo Diario. Martes 12 y 13 de diciembre de 1995. "A la conciencia de la nación”. En La Prensa, 12 y 13 de diciembre de 1995. 
(...) cuentan también, habría que añadir, con la cobardía o posibilidad de otros sectores de la población, y elites urbanas" ${ }^{23}$

Por eso el C.N.U. apropiadamente elevó su denuncia en los términos siguientes:

“Se ha pretendido desinformar a la opinión pública sobre las universidades, su administración y su importancia para la vida nacional. El Ministro de Educación ha construido argumentos artificiales, pretendiendo con ello ocultar su propia responsabilidad y la del Poder Ejecutivo, ante la crítica situación del sector educativo nacional. La agresividad de la campaña anti-universitaria, sin presentar ninguna prueba de las acusaciones, distorsionando la realidad y las estadísticas universitarias, no hacen mas que provocar irritación, especialmente en el estudiantado, lo que podría general algunas reacciones naturales que se aparten de la línea de conducta que la Comunidad Universitaria se ha trazado en esta lucha." 24

\section{Marcha del miércoles 13 de diciembre: Masacre a la Comunidad Universitaria}

La noche del 12 de diciembre después de la toma del aeropuerto internacional Augusto Cesar Sandino, el Comité Nacional ampliado de UNEN se reúne para evaluar el desarrollo de las acciones, concluyendo necesario conservar la disciplina y el nivel cívico con que se venía desarrollando la protesta. Se puntualiza promover la marcha ya convocada para el día siguiente 13 de diciembre en el mejor orden posible. Teniendo de fondo los factores mencionados, a las 9 a.m. del miércoles 13 de diciembre, estudiantes, docentes y trabajadores administrativos de las diferentes universidades del CNU se concentran en la Avenida Universitaria frente a la UCA, para marchar hacia la A.N.

23 Ídem Pág. 7 A.

24 Carta dirigida a los diputados de la Asamblea Nacional por parte del C.N.U. Managua, martes 12 de diciembre de 1995. Ver Anexo No. 3. 
La entusiasta manifestación se puso en movimiento desde la UCA, giró por la rotonda de metro centro en dirección el Hospital Militar Escuela Alejandro Dávila Bolaños y continuó sobre la Avenida Bolívar hacia a la A.N. Mas de 20 mil universitarios marcharon encabezados por los rectores de las universidades del CNU y miembros del Comité Nacional de UNEN, en tanto los otros dirigentes estudiantiles se situaron en diferentes partes de la marcha, animando con los altoparlantes que las diferentes representaciones universitarias traían consigo.

Fue una marcha caracterizada por el entusiasmo universitario. Las representaciones culturales revelaban la inventiva juvenil, las alegorías denunciaban al Gobierno y su política anti universidades, grupos folklóricos animaban con presentaciones desde coloridas carrozas, desde los altoparlantes se alentaba con consignas del $6 \%$. Nadie imaginaba lo que horas después, Nicaragua y la comunidad internacional contemplarían estupefacta y con rabia de condena.

Desde antes que llegaran los primeros manifestantes a las cercanías de la A.N. ya estaban desplazados centenares de policías. Como señaló un diario local, “la preparación policial para la represión era evidente, las tropas antimotines se habían desplegado por centenares, como para una gran batalla planifica con anticipación". ${ }^{25}$ Cuando la marcha fue alcanzando lugar frente la A.N., al congregarse mayor número de estudiantes junto a las vallas puestas por la Policía, se produjo mucha tensión y acto seguido las fuerzas Policiales atacaron indiscriminadamente a la manifestación.

Cayó súbitamente sobre los universitarios una lluvia de bombas lacrimógenas. El efecto de los 25 Diario Barricada. Jueves 14 de diciembre de 1995. Año XVI. No. 5814. Pág. 2 
gases obligó que muchos manifestantes se dispersaron, no obstante, la mayoría no se retiró y plantaron resistencia desigual ante la represión policía. Algunos se defendían lanzando piedras y cualquier objeto que lograban encontrar, otros pocos con lanza morteros.

La represión policial no respetó siquiera a los 12 compañeros y compañeras en huelga de hambre, que a diez días de ayuno, permanecían en delicada condición alojados en una casa de campaña en las inmediaciones del mausoleo a Pedro Joaquín Chamorro. Ellos fueron de los primeros en ser atacados con bombas de gases lacrimógenas, teniendo que ser evacuados del lugar hacia las instalaciones de la U.C.A.

Mientras la Comunidad Universitaria era brutalmente reprimida, dentro de la A.N. por algún tiempo todavía, los diputados continuaron sesionando como si no ocurriera nada. Como si lo que sucedía en las afueras de la A.N. no fuese un asunto en el cual compartían responsabilidad. Paradójicamente, mientras en los alrededores de la A.N. se masacraba a los universitarios, en el plenario de A.N. los diputados aprobaban en su totalidad, la Ley de Procuraduría de los Derechos Humanos. ${ }^{26}$ En medio de la lucha campal que se libraba en las afueras de la A.N., según publicó un diario nacional, el vicepresidente de este poder del Estado, Reynaldo Antonio Tefel (q.e.p.d) del M.R.S., en un inadmisible supremo declaraba "el mayor ejemplo que podemos dar es seguir legislando". ${ }^{27}$

En esas circunstancias una delegación del CNU que minutos antes de iniciar la represión, fue autorizada a ingresar a la A.N. y se encontraba allí, logra conversar con los diputados

26 La Prensa. Jueves 14 de diciembre de 1995. Edición No. 20427. Pág. 1.

27 Ibídem 
Dora María Téllez, William Ramírez, Carlos Gallo, Víctor Talavera, Andrés Robles y María Ramírez, a quienes plantean la urgencia de conformar una comisión que mediara para poner fin a la represión. Propósito que no logran debido las circunstancias y al hecho que un oficial del recinto les señaló que no debían abandonar el lugar por cuanto no les garantizaban su seguridad. ${ }^{28}$

En medio del asfixiante humo de gases lacrimógenos que envolvía varias cuadras alrededor de la A.N Los universitarios se replegaron tomando diferentes direcciones para reagruparse en lugares cercanos donde el gas no los afectaba tanto. Algunos de los dirigentes estudiantiles usaban megáfonos o gritaban para que sus compañeros se reordenaran, guardaran la calma y continuaran la protesta. La represión policial se daba de forma generalizada en diferentes puntos distantes de la A.N.; la Avenida Bolívar, el sector donde fue el Cine González, Telcor, Petronic, San Antonio y otros sectores aledaños, después de las 11 a. m. eran verdaderos campos de batalla.

Un tiempo después los miembros de la bancada del F.S.L.N. Gladys Báez, Marcia Quezada y Nathan Sevilla salieron a intentar detener la acción policial sin lograrlo. En otros puntos donde se desarrollaba el enfrentamiento, los rectores de distintas universidades del C.N.U. que para entonces lograron salir de la A.N. y ante el llamado de la dirigencia estudiantil, intentaron ante los mandos policiales parar las acciones. Registrándose el hecho de que el subcomandante Manuel Lezama, jefe de las fuerzas antimotines ordenara a las autoridades universitarias retirarse del lugar.

28 CENIDH. Informe sobre la represión a los estudiantes universitarios por la Policía Nacional el 13 de diciembre de 1995. Managua 20 de diciembre de 1995. Pág. 7 
La represión no se detuvo y no bastando con gases lacrimógenos, la policía comenzó a lanzar balines, balas de goma y balas en una acción represiva sin precedentes, únicamente vista en los tiempos de la Guardia somocista. La represión continua, incluso con más intensidad, aun cuando los manifestantes no representaban una amenaza para las instalaciones de la A.N. La represión fue cobrando víctimas. Se contabilizaban muchos heridos y otro tanto intoxicados. A 12:15 p. m. en los alrededores del costado norte del parque Luis Alfonso Velásquez, el estudiante de III año de Ingeniería Química de la U.N.I. Gerónimo Urbina recibe un disparo que le parte la medula espinal, sus compañeros lo cargan y es trasladado al hospital Antonio Lenín Fonseca, donde fallece siete días más tarde.

Ante los disparos indiscriminados los universitarios se protegían tirándose al suelo o detrás de los árboles del parque, respondiendo la desigual lucha con consignas por el 6 \%, piedras y morteros. La noticia de un estudiante mortalmente herido subió los ánimos a los que protestaban, otros lloraban de enojo al saberse en desventaja ante las armas de fuego. Pero nadie pensaba de los allí presentes abandonar la protesta, aun en esas condiciones. Y es que el aliento colectivo de la protesta cuando se tiene la razón y la legalidad de su parte se llega a convertir en un ánimo enérgico. Y también, se otorgaba la duda que el disparo a matar fuese un accidente y no una determinación, como efectivamente los hechos que siguieron dejaron en evidencia. 
Luego las balas alcanzaron en el mismo sector entre la entrada del Olof Palme y el parque Luis Alfonso Velázquez al estudiantes Roberto Calderón ${ }^{29}$ con un disparo que le atraviesa el pecho pero logra sobrevivir, luego de trasladarlo de emergencia al hospital Bautista. Tiempo después, Bismarck Santana Tijerino ${ }^{30}$ cae por un disparo que le impacta en la pierna derecha cortándole la arteria femorales, la intensa hemorragia es provisionalmente asistida por un miembro de las brigada de estudiantes de medicina que fija un torniquete vital para contener la hemorragia y llevarlo al hospital Antonio Lenín Fonseca, después de varias intervenciones quirúrgicas pierde su pierna derecha.

En el transcurso de las horas en medio del silbido de las balas y el asfixiante humo de las bombas lacrimógenas, pobladores de los barrios aledaños a la A.N. y miembros de la cooperativa Parrales Vallejos fueron llegando al lugar y se sumaron a la lucha en respaldo de los universitarios. Como a las 2:40 p. m. un grupo de universitarios que se desplazaban por el sector de Petronic, a unos 700 metros de la A.N., se vieron frente a un grupo de policías que les tiran balines y bombas lacrimógenas, las que responden con piedras y consignas del $6 \%$. Se da un intercambio, de pronto un policía se adelanta al grupo, apunta y dispara desde corta distancia al compañero Ernesto Porfirio Ramos, trabajador de la EIAG de Rivas, que cae muerto con el cráneo perforado. Según la testigo ocular, Yamileth Vargas, que en ese momento habitaba frente donde cayó asesinado Porfirio Ramos y pudo observar la acción, el disparo fue realizado casi a quemarropa por uno de los policías. ${ }^{31}$ Mientras las unidades de la Cruz Roja y 29 Presidente del Comité Electoral Nacional de UNEN.

30 Después de esto llegó a ser presidente de UNEN en el RURD y Presidente de la UNEN-Nacional.

31 Boletín Informativo del Centro Nicaragüense de Derechos Humanos (CENIDH). Año 6. No. 32. marzo/abril. 1996. Pág. 6. 
del Cuerpo de Bomberos ingresaban a zona de forma sistemática, el enfrentamiento desigual de balas contra piedras y morteros, dejaba como consecuencia para la Comunidad Universitaria muertos y heridos.

En el transcurso de la lucha campal los universitarios lograron capturar a dos policías, el sargento Juan Francisco Cuaresma y Freddy Antonio Mendieta. Esta situación puso a prueba la capacidad de conducción y autoridad de la dirigencia estudiantil. Resistiéndose a la indignación y furia de los universitarios, que ante los muertos y heridos, pedían hacer justicia por sus propios medios, los dirigentes lograron preservar la integridad física de estos policías. Ese fue, de los muchos, un momento de lo más tenso. Finalmente, los policías fuera de haber recibido algunos golpes, fueron entregados ilesos al personal del CENIDH, que a su vez los entregó al capitán Manuel García, asistente del Inspector General de la Policía Nacional.

Cerca de las 5 p. m. los dirigentes estudiantiles usando altoparlantes y megáfonos, hacen esfuerzos para reconcentrar a los manifestantes, orientando retirarse hacia la U.C.A. Tarea difícil considerando los miles de manifestantes que se desplazaban en un perímetro de cerca de 1 kilómetro. La dirigencia estudiantil finalmente condujo a los manifestantes hacia la U.C.A, en la marcha, pasando por el paseo de Tiscapa es significativo el gesto realizado, cuando unos estudiantes bajan a media asta, en señal de luto, una bandera de Nicaragua allí ubicada.

La criminal acción policial que se extendió por más de 4 horas, fue justificada en palabras del Jefe Nacional de la Policía Fernando Caldera, como resultado de la presión a que se vieron 
sometidos los policías. Sin embargo, era innegable que la policía tenía desplegado un enorme dispositivo acordonando las instalaciones de la Presidencia de la República y la A.N., como evidencia que se preparaban para una acción a escala mayor. Además, estaba bloqueada con una valla metálica la calle que divide la A.N. con el parque Luís Alfonso Velásquez, extendiéndose el cordón policial sobre la acera del Parque y el edificio del Ministerio de Finanzas, hacia el Este, en dirección al Olof Palme. Detrás del cordón policial estaban policías formados en diferentes escalones, con distintos armamentos; antimotines con todo su equipo, otros con fusiles $\mathrm{AK}$, escopetas y pistolas. ${ }^{32}$

El dispositivo policial estaba suficientemente apertrechado como para manejar una situación sin recurrir a los extremos de disparar a matar. Aún es válida la interrogante formulada en el editorial diario Barricada del jueves 14 de diciembre de 1995: ¿Quién dio la orden de ignominia, de la represión y el crimen?, ¿Quién osó emular la criminal barbarie somocista de 1959 sobre los estudiantes?, ¿Quiénes solicitaron de las fuerzas del orden semejante represión?, ¿Quiénes son los ministros pusilánimes que han permitido la hostilidad y la agresión contra los estudiantes y el $6 \%$ ?. $^{33}$

La represión del 13 de diciembre, sostenida en el tiempo, desde las 11 a. m. a las 5 p. m. aproximadamente, y en la forma, la policía siempre mantuvo su formación de ataque, fue claro que no se limitó únicamente a proteger las instalaciones de la A.N. ${ }^{34}$ La persecución 32 CENIDH. Informe sobre la represión a los estudiantes universitarios por la Policía Nacional el 13 de diciembre de 1995. Managua 20 de diciembre de 1995. Pág. 3. 33 Diario Barricada. Año 17. No. 5814. Jueves 14 de diciembre de 1995. Pág. 3. 34 Recordemos que Ernesto Porfirio Ramos es asesinado aproximadamente a 700 metros de distancia de la A.N. 
desatada contra los universitarios estaba dirigida a reprimir, desalojar, intimidar y liquidar la protesta. Es absurdo el argumento que los disparos se produjeron por la presión del momento y mas condenable, aun, es la actitud tomada por la presidenta Violeta Barrios de Chamorro, el Ministro de la Presidencia y el de Gobernación, al no haber ordenado, ninguno de ellos, parar la represión que se extendió más de 5 horas y que por las transmisiones de televisión y radio, el pueblo de Nicaragua fue testigo.

Las condenas a la acción policial vinieron de organismos nacionales e internacionales, de diferentes gremios del país, de organismos estudiantiles de Centroamérica y del pueblo nicaragüense en general. Todos repudiaban y condenaban la represión policial con comunicados, cartas y pronunciamientos en los que demandaban al Gobierno y a la A.N. respetar la Constitución Política y cumplir con el 6 \%. Como señaló acertadamente un artículo del momento:

“el 13 de diciembre será rememorado, para siempre como el día en que la señora Violeta Barrios de Chamorro, presidenta de Nicaragua, abochornó al género femenino: no reaccionó ni como madre, ni como abuela, ni como cristiana (...) a los clamores del estudiantado, profesores, periodistas, trabajadores y pueblo en general, para que ordenara el paro a la represión (...) en contra de la Comunidad Universitaria..."35 La sangre y vida de Ernesto Porfirio Ramos y Jerónimo Urbina, la salud y estabilidad emocional de las decenas de heridos “quedarán como estigma imborrable en la vida de doña Violeta, la primera mujer presidenta de Nicaragua que ordenó la masacre mas inhumana de los últimos tiempos de la historia de Nicaragua" 36

35 Aldana Saracini, Aura Violeta. El Gobierno de doña Violeta y el $6 \%$. El Nuevo Diario. Año XVI. No. 5566. Miércoles 20 de diciembre de 1995. Pág. 6.

36 Ibíd. 
Concluyentemente el Centro Nicaragüense de Derechos Humanos (CENIDH), en su informe sobre la represión a los estudiantes universitarios por la Policía Nacional, dejó claro que la policía comenzó a disparar balines, pelotas de goma e incluso balas. ${ }^{37}$ El equipo del CENIDH que hizo presencia al lugar de los hechos informó:

"Pudimos constatar que la acción de las fuerzas del orden público no se limitó a proteger las instalaciones del parlamento. Por el contrario, fuimos testigos de la persecución desatada, claramente dirigida a reprimir, desalojar, intimidar y liquidar la protesta. En tal sentido la Policía se desplazó en cuatro flancos principales, en ellos en diferentes momentos, el CENIDH presencio la represión policial: 1) Parque Luis Alfonso Velásquez, 2) Grupo que se desplazó hacia el sur, o sea, a la zona del busto Simón Bolívar, 3) Zona del ministerio de finanzas hacia el este, distrito 4 de la alcaldía, Olof Palme y Empresa Petronic, 4) Grupo que se desplazaba sobre la avenida Bolívar hacia el norte, desde la Asamblea Nacional hasta las instalaciones de Microfer y frente al cine González."38

Después de los hechos, mediante un comunicado, el Ministerio de Gobernación señaló que la Policía como garante del orden público y la seguridad ciudadana, resguardaba las instalaciones en las que sesionaban los diputados y en un abuso contra la inteligencia del pueblo

37 Informe sobre la represión a los estudiantes universitarios por la Policía Nacional, el 13 de diciembre de 1995. Centro Nicaragüense de Derechos Humanos (CENIDH). Managua, 20 de diciembre de 1995. Pág. 3.

38 Ibídem. 
nicaragüense, afirmaban, que "la fuerza policial fue obligada a utilizar la técnica establecida, dispersando con bombas lacrimógenas a los manifestantes." ${ }^{39}$

Por su parte el jefe de la Policía Nacional, Fernando Caldera, arguyó que los altos mandos policiales no intervinieron cuando se comenzó a disparar, porque fue “(...) una situación muy difícil y muy confusa la que se presentó" 40 . Aseverando, según él; "No hubo ninguna orden de usar armas de fuego en contra de los manifestantes"41. Al justificar el actuar de la policía, señaló, "fuimos objeto de una agresión; rompieron la barrera de seguridad a pedradas. Los policías sometidos a un estrés y alta tensión dispararon (...), ${ }^{42} \mathrm{e}$ intentando justificar la masacre, señalaba que "en la protesta universitaria se involucraron elementos extraños a la Comunidad Universitaria", como tal eventualidad justificara el uso de armas de fuego contra manifestantes indefensos. ${ }^{43}$

Un discurso parecido encaminado a restar legitimidad a la protesta universitaria, también se pudo escuchar dos días después del 13 de diciembre, cuando en los debates por el Presupuesto General de la República, el viernes 15 de diciembre, la diputada de derecha, Azucena Ferrey se interrogaba irónicamente: “Conversando con mi amigo y compañero Adán Fletes, le preguntaba si en la historia reciente vivida por nosotros en la década de los 60 y 70 había algún precedente en que los dirigentes estudiantiles se hubiesen convertido en los directores de la

39 El Nuevo Diario. Año XVI. No. 5510. Jueves 14 de diciembre de 1995. Pág. 2.

40 El Nuevo Diario. Año XVI. No. 5511. Viernes 15 de diciembre de 1995. Pág. 8.

41 La Tribuna. Año. III. No. 881. Viernes 15 de diciembre de 1995. P. 5-A.

42 Ibídem

43 Ibídem. 
represión, y no recordaba" ${ }^{44}$

Como si los responsables de los sucesos fueran los estudiantes y no las violaciones constitucionales del gobierno. Mas allá de eso, en medio de los trágicos sucesos, la UNEN experimentó un fortalecimiento indiscutible. Esta dura experiencia consolidó al Movimiento Estudiantil y lo colocó decididamente al frente de la Comunidad Universitaria en la defensa del $6 \%$ y la Autonomía.

\section{Conclusiones}

Los hechos del miércoles 13 de diciembre de 1995 se enmarcan en la lucha realizada por la Comunidad Universitaria basándose en el reconocimiento expreso del Art. 125 de la Constitución Política que establece el 6 \% del Presupuesto General de la República para las Universidades y Centros de Educación Técnica Superior del C.N.U.

La violación por parte del Gobierno al marco de legalidad constitucional es el trasfondo que provocó la protesta universitaria que recurrió a acciones de diferentes maneras para hacer valer lo que en derecho les corresponde. Antes del 13 de diciembre la Comunidad Universitaria realizó varias marchas y tomas de edificios estatales para llamar la atención al Gobierno y negociar junto al C.N.U. una salida viable para que se cumpliera con el $6 \%$.

Frente a la demanda de la Comunidad Universitaria el Gobierno decididamente se negó a

441995 Memorias parte Final sesión ordinaria No. 10. Pág. 1581. Sesión especial de elección de vice-presidente de la República. Sesión de Clausura. Tomo X. Biblioteca de la Asamblea Nacional de Nicaragua. Pág. 1590. 
entrar en negociaciones con el C.N.U. sobre la propuesta gubernamental para el Presupuesto General. Mas bien el Ministro de Educación Humberto Belli, realizó una campaña pública para tratar de deslegitimar la lucha universitaria, tratando de crear una confrontación entre el Sistema de Educación Superior y la Educación Básica, sobre la base de un discurso de confrontación y recurriendo a argumentos que distorsionaban la verdad e importancia del tema del financiamiento de la Educación Superior.

La misma falta de sensibilidad del Gobierno ante la protesta se reflejó en el hecho mismo que no tiene explicación que durante los sucesos del 13 de diciembre no hubo ninguna actuación gubernamental para detener la masacre que se prolongó durante varias horas. Prácticamente en las inmediaciones de la propia casa presidencial, a pesar de numerosos y urgentes llamados de amplios sectores de la sociedad que solicitaban a la presidencia y su Gobierno que intervinieran y pararan la represión.

La desproporcionalidad de la pretendida acción policial "Para repeler la agresión de los estudiantes" se evidencia claramente en las pruebas recogidas y los resultados reflejados en la cantidad de muertos y heridos; asimismo en las características de las lesiones que los mismos recibieron. Es un hecho que el número de policías lesionados fue mucho menor (8) y ninguno de ellos fue herido con armas de fuego, las lesiones que presentaron, fueron productos de pedradas; mientras por la Comunidad Universitaria resultaron dos compañeros muertos por armas de fuego y 65 lesionas por armas de fuego, charneles, balines y bombas lacrimógenas.

La Policía violó su propia Ley y el Principio de Proporcionalidad, establecido en los 
Principios Básico sobre el empleo de la fuerza y armas de fuego, para los funcionarios encargados de hacer cumplir la Ley, y el Código de Conducta para esos mismos funcionarios. Instrumentos internacionales de cumplimiento obligatorio para cualquier cuerpo armado o del mantenimiento del orden interno (que son recogidos por la Ley Orgánica de la Policía Nacional). Tal irrespeto violó el derecho a la vida de dos manifestantes, la integridad física de al menos 65 personas que sufrieron lesiones y expuso al peligro la vida, integridad física y seguridad de miles de manifestantes y pobladores de los barrios aledaños.

La masacre universitaria del miércoles 13 de diciembre de 1995, marcó a toda una generación de estudiantes universitarios, docentes y trabajadores administrativos, y quedó perpetuada en la memoria histórica como una afrenta a la dignidad humana y el Estado de derecho en el modelo "democrático" del gobierno de doña Violeta Barrios de Chamorro. 